\title{
INVITED COMMENTARY
}

\section{Turner syndrome}

\author{
M B Ranke \\ Kinderklinik, Eberhard-Karls-Universität Tübingen, Hoppe-Seyler-Strasse 1, D-72076 Tübingen, Germany
}

Turner syndrome (TS) is caused by the structural abnormality or absence of one X-chromosome. Typical karyotypes are 45,X (approx. 50\%), 46,X,i(Xq), and 46,X,rX. Mosaicism occurs when normal and abnormal cell lines are combined (e.g. 45,X/46,XX). TS is a rather frequent disorder (approx. 1:2500 live-born phenotypical females) which is characterized by three main clinical features: (i) abnormalities in external appearance and of some internal organs; (ii) malformation of the ovaries, resulting in primary hypogonadism in the majority of cases $(80 \%-90 \%)$; (iii) short stature, this being the most constant finding in Turner syndrome and not attributable to disorders in growth hormone (GH) secretion (1).

Reports on adult height vary (2). The mean adult stature in patients of Caucasian origin is approximately 142 to $147 \mathrm{~cm}$. Comparative data on adult height in patients with different ethnic backgrounds show a disparity of up to $20 \mathrm{~cm}$ between TS patients and the normal mean for a given population. The findings of Hochberg and Zadik (3) support these observations further. The variability in height, however, is similar in magnitude to that observed in the normal population, and, likewise, there is a positive correlation between parental height and adult height.

Several attempts are being made to predict adult height, the most widely accepted model being one in which height increment is plotted on a TS-specific growth chart and 'projected adult height' (PAH) is taken to be the mathematical extension of the line emerging from the individual centile of observed growth. The validity of this approach is supported by empirical evidence (4). It appears to be quite sound, as it assumes that childhood growth in TS follows the channel of targeted height, and that individual influences on a child's growth (e.g. parental height) are already expressed as the disease-specific deviation of height from the mean values of normal children for a given age. The availability of disease-specific references for height and their practicality in predicting individual adult height are the basis on which treatment attempts are made in correcting short stature in TS. The prevailing controversy, however, concerns the question of whether historical growth references should be used in planning growth-promoting treatment. The best that can be said, at present, to defend the practice of using historical references is that the patients treated with GH display the same auxological pattern as the historical controls and that there is no convincing evidence for a major secular trend in TS. Thus, any methodological error occurring during common practice is likely to be insignificant. Nevertheless, randomized and controlled studies of sufficiently large cohorts are probably the best means of excluding biases.

In recent times, the production of $\mathrm{GH}$ through the recombinant technique has made abundant amounts of $\mathrm{GH}$ available, thus making evaluative studies on this treatment possible. Several international meetings have been held towards further understanding of the mechanisms of growth, GH treatment and other aspects of TS $(1,5-7)$. The prototype of all recent studies is that initiated in 1987 by the Genentech Study Group, successive reports of which have been published (8). In this study, a representative cohort of 70 TS patients was given $\mathrm{GH}$ treatment in a multicenter, prospective, randomized trial. Treatment comprised either GH alone, or in combination with oxandrolone (OX). In the first year, patients were randomized into four groups (control, GH alone, OX alone, GH plus OX). In the following year, the study of only two groups continued (GH, GH plus $\mathrm{OX})$. In all, 60 of the original patients (GH: $n=17$; GH plus $\mathrm{OX}: n=43$ ) have now completed the trial. The decision to drop the control group was criticised and has raised an ongoing debate. Recently, the authors reported on 25 American historical controls matched to the study patients and followed to final height. The dose of GH was $0.375 \mathrm{mg} /$ $\mathrm{kg} /$ week (approx. 1.0 IU/kg/week), divided into daily injections. The dose of $\mathrm{OX}$ was $0.0625 \mathrm{mg} / \mathrm{kg} / \mathrm{day}$. Estrogen substitution began at a mean age of 15 years. While the control group reached an adult height of $144.2 \pm 6.0 \mathrm{~cm}$, the $\mathrm{GH}$ and $\mathrm{GH}$ plus $\mathrm{OX}$ patients reached $150.4 \pm 5.5$ and $152.1 \pm 5.9 \mathrm{~cm}$ respectively. The difference between the treated groups is not significant. The gain beyond $\mathrm{PAH}$ averaged about $8 \mathrm{~cm}$, with many patients continuing to grow.

Growth hormone treatment as a means of correcting short stature in TS has become common practice in many countries and the costs are frequently reimbursed by health authorities or insurance companies. Yet this treatment - either alone or in combination with oxandrolone - continues to be the subject of an ongoing controversy (9). The main argument proposed against the suitability of such a study is that it does not include a randomized, untreated (placebo-treated) control group followed to final height. Besides this, the validity of a comparison based on historical controls has been questioned. The study by Rosenfeld et al. (8) 
has secondarily introduced a control group, which remarkably - reached exactly the PAH expected. In the treated groups, however, height values greatly exceeded the predicted values. A gain in height over and beyond the expected PAH increment of approximately $10 \mathrm{~cm}$ is definitely not incidental, and it proves the efficacy of this mode of treatment. Nevertheless, some of the results - including those reported in the present issue of European Journal of Endocrinology (3) - have been less favourable. This raises the question of which factors - in this study and in general - are of importance in achieving an optimal gain in height. Hochberg and Zadik (3) drew two conclusions from their study: (i) 'GH therapy can be initiated after age 10 ', and (ii) 'there is no reason to delay estrogen beyond the age of 12'. These statements contradict the general evidence available and are probably biased.

Current knowledge indicates three major factors that might be relevant to favorable height outcome in TS.

\section{Age at onset of treatment: the lower, the better}

In the American study, age at onset was the lowest of all reported studies. The height of TS patients at 10 years of age is approximately $120 \mathrm{~cm}$. An additional gain of $10 \mathrm{~cm}$ represents $40 \%$ of the remnant spontaneous growth, and is obviously difficult to gain. Some of the poor results are certainly attributable to the late start of GH treatment, and result from the fact that late starters are the earliest to reach adult height. The cost effectiveness of treating younger (lighter) children is a further reason for an early start of treatment.

\section{GH dose: the more, the better}

The dose of GH used in Hochberg and Zadik's study (3) was approximately $0.8 \mathrm{IU} / \mathrm{kg} /$ week compared with approximately $1.0 \mathrm{IU} / \mathrm{kg} /$ week in the Rosenfeld study (8). Two recent studies $(10,11)$ have convincingly demonstrated the importance of higher doses as well as of dose adjustment.

\section{Age at onset of estrogen substitution: the later, the better}

Estrogens are potentially disadvantageous to growth. In the Rosenfeld study (8), estrogens were introduced favorably at a later timepoint. There is no doubt that the appropriate timing of pubertal development is important for any girl. Thus the decision to introduce estrogens needs to be made after assessing a variety of individual aspects of which height is only one. From the point of view of growth alone, however, the optimal age for the introduction of estrogen is probably between 13 and 14 years. At this point in time it can be stated without doubt that GH treatment improves height in TS. Future developments should concentrate on optimizing treatment on an individual basis, with regard to the timing of the start of GH therapy, dosage adaptation, and the introduction of concurrent therapy with OX or estrogens.

In scheduling GH treatment of short stature in TS, two further aspects must be considered, the foremost among them being safety. Long-term therapy involving supraphysiological GH doses but administered in an unphysiological mode (i.e. one daily GH bolus), may pose long-term risks to metabolism. At this point in time, however, it can be concluded that the short-term (few years) safety record in TS has been almost as good as in $\mathrm{GH}$ substitution in growth hormone-deficient patients (12). Finally, the optimization of treatment also needs to incorporate aspects relating to the quality of life of TS patients as well as the costs involved. Gain in height needs to be viewed within the context of an individual's perspectives in life which are subject to development and change.

\section{References}

1 Ranke MB \& Rosenfeld RG (eds). Turner Syndrome: Growth Promoting Therapies. Excerpta Medica International Congress Series 924. Amsterdam: Excerpta Medica, 1991.

2 Ranke MB \& Grauer ML. Adult height in Turner syndrome: results of a multinational survey 1993. Hormone Research 1994 42 90-94.

3 Hochberg Z \& Zadik Z. Final height in young women with Turner syndrome after GH therapy: an open controlled study. European Journal of Endocrinology 1999141 218-224.

4 Lyon AJ, Preece MA \& Grant DB. Growth curve for girls with Turner syndrome. Archives of Diseases in Childhood 1985 $60932-935$.

5 Rosenfeld RG \& Grumbach MM (eds). Turner Syndrome. New York: Marcel Dekker, 1989.

6 Hibi I \& Takano K (eds). Basic and Clinical Approach to Turner Syndrome. Excerpta Medica International Congress Series 1014. Amsterdam: Excerpta Medica, 1993.

7 Albertsson-Wikland K \& Ranke MB (eds). Turner Syndrome in a Life Span Perspective: Research and Clinical Aspects. Excerpta Medica International Congress Series 1089. Amsterdam: Excerpta Medica, 1995.

8 Rosenfeld RG, Attie KM, Frane J, Brasel JA, Burstein S, Cara JF et al. Growth hormone therapy of Turner's syndrome: beneficial effect on adult height. Journal of Pediatrics 1998132 319-324.

9 Donaldson MDC. Growth hormone therapy in Turner syndrome current uncertainties and future strategies. Hormone Research 199748 (Suppl) 35-44.

10 Van Teunenbroek A, de Muinck Keizer-Schrama SMPF, Stijnen T, Jansen M, Otten BJ, Delemarre Van de Waal HA et al. Yearly stepwise increments of the growth hormone dose results in a better growth response after four years in girls with Turner syndrome. Journal of Clinical Endocrinology and Metabolism 1996 81 4013-4021.

11 Carel JC, Mathivon L, Gendrel C, Ducret JP \& Chaussain JL. Near normalization of final height with adapted doses of growth hormone in Turner's syndrome. Journal of Clinical Endocrinology and Metabolism 199883 1462-1466.

12 Wilton P. Adverse events during GH treatment: 10 years' experience in KIGS a pharmacoepidemiological survey. In Growth Hormone Therapy in KIGS - 10 Years' Experience. Eds MB Ranke \& P Wilton. Heidelberg: Barth Verlag, 1999. 